\title{
Cytogenetic and histological studies of the brook trout, Salvelinus fontinalis (Mitchill), and the Arctic char, S. alpinus (L.) hybrids
}

\author{
Konrad Ocalewicz • Piotr Hliwa • Konrad Pomianowski • \\ Rodrigo Lisboa $\cdot$ Malgorzata Jankun
}

Received: 30 January 2013/Accepted: 18 May 2013/Published online: 26 May 2013

(C) The Author(s) 2013. This article is published with open access at Springerlink.com

\begin{abstract}
Although brook trout and the Arctic char hybrids are able to reproduce, individuals with decreased fertility or even fish that are unable to produce any gametes have been also described. Abnormal gonadal development and disturbances in the gamete production in the char hybrid offspring may be triggered by the odd chromosome number and disturbances in their pairing during meiosis. To verify this hypothesis, cytogenetic examination and the gonadal histology analysis of the brook trout $\mathrm{x}$ Arctic char hybrids were carried out. Diploid chromosome number in the studied char $\left(\mathrm{F}_{1}\right)$ hybrids varied from 82 to 84 ( $\mathrm{FN}=99-102)$. Among 28 hybrids, 12 males, three females, nine intersex individuals and two sterile specimens were described. In the case of two individuals, gonads were not found. Diploid chromosome numbers in the males and intersex individuals varied from 82 to 84 . Chromosome numbers in the females were 82 and 83 chromosomes. Two sterile fish exhibited karyotypes composed of 82 and 84 chromosomes. Predominance of the ovarian component in the intersex gonads and gonadal sex ratio distortion towards the males suggested hybrid females had problems with gonadal differentiation. However, the lack of the clear relationship between chromosome number and gonadal development in the studied hybrids did not support our hypothesis that odd chromosome number may be responsible for such reproductive disturbances in the hybrid individuals. We have presumed that sterility and intersexual development of the gonads may be caused by interactions between brook trout and Arctic char genes on the sex chromosomes and autosomes rather than unpairing of the parental chromosomes.
\end{abstract}

Keywords Chromosomes $\cdot$ Gonads $\cdot$ Intersex $\cdot$ Reproduction $\cdot$ Sex differentiation

K. Ocalewicz $(\bowtie) \cdot$ P. Hliwa $\cdot$ K. Pomianowski $\cdot$ M. Jankun

Department of Ichthyology, University of Warmia and Mazury in Olsztyn, ul. Oczapowskiego 5, 10-719 Olsztyn, Poland

e-mail: con@uwm.edu.pl

R. Lisboa

Faculty of Science and Technology, University of Algarve, Faro, Portugal 


\section{Introduction}

The main aim of the fish interspecific hybridization approach is to produce progenies exhibiting better characteristics when compared to the parental species. Interspecific hybrid fishes have been proposed to be utilized in aquaculture and stocking programs to increase growth rate, combine valuable traits of two species, support disease resistance and produce mono-sex progenies (Bartley et al. 2001). Sometimes, interspecific crosses result in progenies exhibiting decreased reproductive capacity or even sterility that is related to the problems with gonadal development caused by the incompatibility of the parental sets of chromosomes. Production of the sterile fish may reduce the overall costs of the fish rearing as such individuals do not experience decline in growth, survival and meat quality quite frequently observed at the early sexual maturation of the normal fish. Moreover, sterile specimens minimize the risk of unwanted reproduction. So far, several sterile interspecific hybrids like tiger trout (Salmo trutta $\times$ Salvelinus fontinalis), sunshine bass (Morone chrysops $\times$ M. saxatilis), gilthead seabram (Sparus aurata) $\mathrm{x}$ red seabream (Pagrus major) have been described and proposed to be utilized in aquaculture (Bartley et al. 2001). Recently, special attention has been dedicated to the brook trout (Salvelinus fontinalis) $\times$ Arctic char (Salvelinus alpinus) hybrids as their meat is highly appreciated by consumers in several places in Europe (Gross et al. 2004). Although brook trout and Arctic char hybrids are able to reproduce, individuals with decreased fertility or even fish that are unable to produce any gametes have been also described. Diploid chromosome number in the brook trout is invariably 84, while Arctic char exhibits chromosome number that may range from 78 to 84 (Phillips and Ráb 2001). Thus, reproductive problems including abnormal gonadal development and disturbances in the gamete production in the brook trout and Arctic char hybrids can be caused by the odd chromosome number and suppression in their pairing during meiosis. To verify this hypothesis, cytogenetic examination and the gonad histology analysis of the brook trout x Arctic char hybrids were carried out.

\section{Materials and methods}

Brook trout eggs and Arctic char spermatozoa were collected from the broodstocks kept at 6-8 ${ }^{\circ} \mathrm{C}$ at the Department of Salmonid Research, Inland Fisheries Institute in Olsztyn, Rutki, Poland. Individuals from the brook trout broodstock are characterized by a diploid chromosome number $(2 n)$ and a chromosome arm number, FN (Fundamental Number), which are 84 and 100, respectively (Ocalewicz et al. 2004). In the Arctic char individuals from Rutki broodstock, diploid chromosome number varies from 81 to 82 (FN = 100) (Pomianowski et al. 2012). Brook trout eggs collected from four females were inseminated with the spermatozoa from one Arctic char male. Inseminated eggs were incubated at $6-8{ }^{\circ} \mathrm{C}$ under routine programme conditions performed at the Departments of Salmonid Research, Rutki.

For the cytogenetic and histological analysis, twenty-eight hybrid individuals were sampled after 8 months of rearing (H1-6) and after 15 months of rearing (H13-H34) (Table 1).

Metaphase spreads were obtained from the cell suspensions of the cephalic kidney according to Ocalewicz et al. (2008). Chromosomes were stained with buffered Giemsa $(10 \%)$ and 4, 6-diamidino-2-phenylindole (DAPI) for visualization and description of the chromosomal morphology. Metaphase plates were analysed under a Zeiss Axio Imager A1 microscope equipped with a fluorescent lamp and a digital camera. Images were captured, 
Table 1 Results of the karyological and histological examination of the brook trout (Salvelinus fontinalis) $\times$ Artcic char (Salvelinus alpinus) $\mathrm{F}_{1}$ hybrids $(\mathrm{H})$

\begin{tabular}{|c|c|c|c|}
\hline Fish & $\begin{array}{l}\text { Chromosome } \\
\text { number }(2 n)\end{array}$ & $\begin{array}{l}\text { Chromosome arm } \\
\text { number (FN) }\end{array}$ & Gonadal histology \\
\hline $\mathrm{H} 1$ & 84 & 100 & Gonads not found \\
\hline $\mathrm{H} 2$ & 84 & 100 & Intersex \\
\hline H3 & 83 & 100 & Male \\
\hline $\mathrm{H} 4$ & 83 & 100 & Male \\
\hline H5 & 84 & 100 & Male \\
\hline H6 & 84 & 100 & Male \\
\hline H13 & 83 & 100 & Intersex \\
\hline H14 & 82 & 99 & Male \\
\hline H15 & 84 & 100 & Male \\
\hline H16 & 82 & 99 & Intersex \\
\hline H17 & 83 & 100 & Female \\
\hline H18 & 83 & 100 & Intersex \\
\hline H19 & 82 & 100 & Female \\
\hline $\mathrm{H} 20$ & 82 & 99 & Intersex \\
\hline $\mathrm{H} 21$ & 83 & 100 & Male \\
\hline $\mathrm{H} 22$ & 83 & 99 & Male \\
\hline $\mathrm{H} 23$ & 84 & 101 & Intersex \\
\hline $\mathrm{H} 24$ & 84 & 99 & Male \\
\hline $\mathrm{H} 25$ & 82 & 99 & Sterile \\
\hline H26 & 83 & 100 & Male \\
\hline $\mathrm{H} 27$ & 83 & 100 & Intersex \\
\hline $\mathrm{H} 28$ & 84 & 100 & Gonads not found \\
\hline $\mathrm{H} 29$ & 84 & 100 & Sterile \\
\hline H30 & 84 & 100 & Male \\
\hline H31 & 84 & 102 & Intersex \\
\hline H32 & 83 & 100 & Male \\
\hline H33 & 82 & 99 & Female \\
\hline H34 & - & - & Intersex \\
\hline
\end{tabular}

and the electronic processing of the images was performed using Band View/FISH View software (Applied Spectral Imaging).

Histological analysis of the karyologically studied hybrid individuals was carried out to confirm gonadal sex of the fish. Fragments of gonads were collected and fixed in Bouin's solution. Subsequently, the tissues were dehydrated in alcohol, fixed in xylene and embedded in paraffin blocks. Slices of 4-5 $\mu \mathrm{m}$ thick were cut using a rotational microtome model RM 2155 (LEICA Microsystems, Wetzlar, Germany) and stained with haematoxylin and eosin (HE method) (Zawistowski 1986). Histological analyses of cross-sections for the shape, size and the type of germ cells present in gonads were made with LEICA DM 3000 transmission light microscope and micro image computer analysis software LEICA QWin Pro (LEICA Microsystems AG, Heerbrugg, Switzerland). The nomenclature of germ cells and cellular structures was used according to Hliwa et al. (2002) and Schulz et al. (2010). 


\section{Results}

Diploid chromosome number in the studied $F_{1}$ char hybrids varied from 82 to 84 $(\mathrm{FN}=99-102)$ (Fig. 1). Low number and poor quality of the metaphase spreads made us unable to properly evaluate chromosomes number and morphology in one specimen (Table 1). Among 28 hybrids, three females, 12 males, nine intersex individuals and two asexual or sterile specimens were described. In the case of two individuals, gonads were not found (Table 1) (Fig. 2). The three females were at the early vitellogenic stage of the gonadal development, and previtellogenic and early vitellogenic oocytes were observed in their gonads. Both types of the oocytes were surrounded by the layers of the follicular cells. Previtellogenic oocytes observed at the periphery of the ovarian lamellae exhibited many nuclei located at the margin of the nuclear membrane (Fig. 2a).

Histological analysis of the male gonads exhibited testicular tissue with seminal vesicles and spermatogenic cells at the different stages of spermatogenesis including spermatogonia, primary spermatocytes and secondary spermatocytes (Fig. 2b). Gonads of the mosaic type with larger ovarian component and considerably smaller and randomly distributed testicular portions were observed in all of the intersex specimens. The female

a

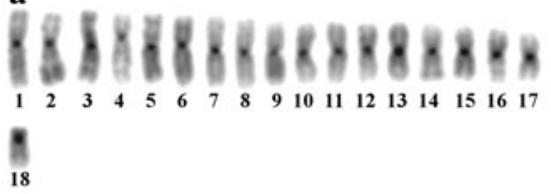

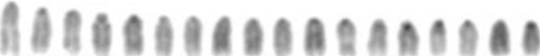

$\begin{array}{llllllllllllllllll}19 & 20 & 21 & 22 & 23 & 24 & 25 & 26 & 27 & 28 & 29 & 30 & 31 & 32 & 33 & 34 & 35 & 36\end{array}$ A A A A A A A A A B A A A A A A A $\begin{array}{llllllllllllllllll}37 & 38 & 39 & 40 & 41 & 42 & 43 & 44 & 45 & 46 & 47 & 48 & 49 & 50 & 51 & 52 & 53 & 54\end{array}$ A A A A A A A A A A A A A A A $\begin{array}{lllllllllllllllll}55 & 5657 & 58 & 59 & 60 & 61 & 62 & 63 & 64 & 65 & 66 & 67 & 68 & 69 & 70 & 71 & 72\end{array}$ A A A A A A $\mathrm{A}$ A

$737475 \quad 76 \quad 777879808182$

c

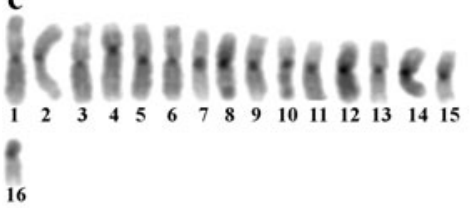

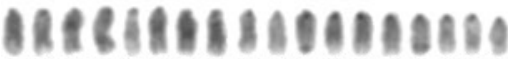

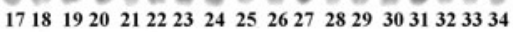

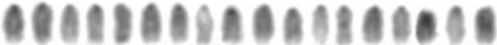

$353637383940414243 \quad 44 \quad 45464748 \quad 4950 \quad 5152$

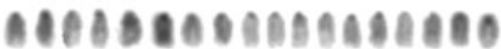

$5354555657585960616263646566 \quad 67686970$

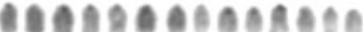

7172737475767778798081828384 b

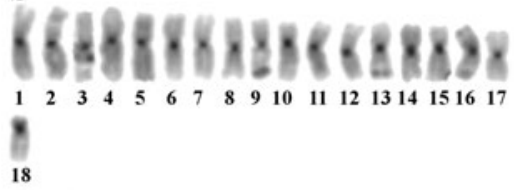

crerinemparmomene $1920212223 \quad 24252627282930 \quad 31 \quad 3233 \quad 343536$

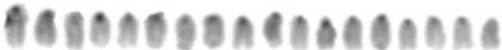
$373839404142 \quad 43444546 \quad 4748495051 \quad 525354$ AOA A A A A A A A A A A A A A $555657585960616263646566 \quad 676869707172$ A A A A A A A A A A 7374757677787980818283

d

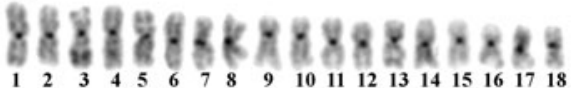
4 19

GANAOQBAORBQABOEBO $\begin{array}{lllllllllllllllllll}20 & 21 & 22 & 23 & 24 & 25 & 26 & 27 & 28 & 29 & 30 & 31 & 32 & 33 & 34 & 35 & 36 & 37\end{array}$

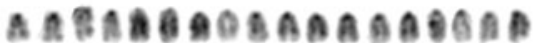
$\begin{array}{llllllllllllll}38 & 39 & 40 & 41 & 42 & 4344 & 45 & 46 & 47 & 48 & 49 & 5051 & 525354 & 55\end{array}$ DAABARABRABDOABABA $\begin{array}{lllllllllllllll}56 & 5758 & 5960 & 61 & 62 & 63 & 64 & 6566 & 6768 & 69 & 70 & 71 & 72 & 73\end{array}$

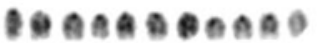
7475767778798081828384

Fig. 1 Karyotypes of the brook trout $\times$ Arctic char hybrids after DAPI fluorochrome staining showing variable chromosome numbers; $2 n=82, \mathrm{NF}=99$ (H33 female) (a), $2 n=83, \mathrm{NF}=100$ (H13 intersex) (b), $2 n=84, \mathrm{NF}=99$ (H24 male) (c) and $2 n=84, \mathrm{NF}=102$ (H31 intersex) (d). Bar equals $10 \mu \mathrm{m}$ 

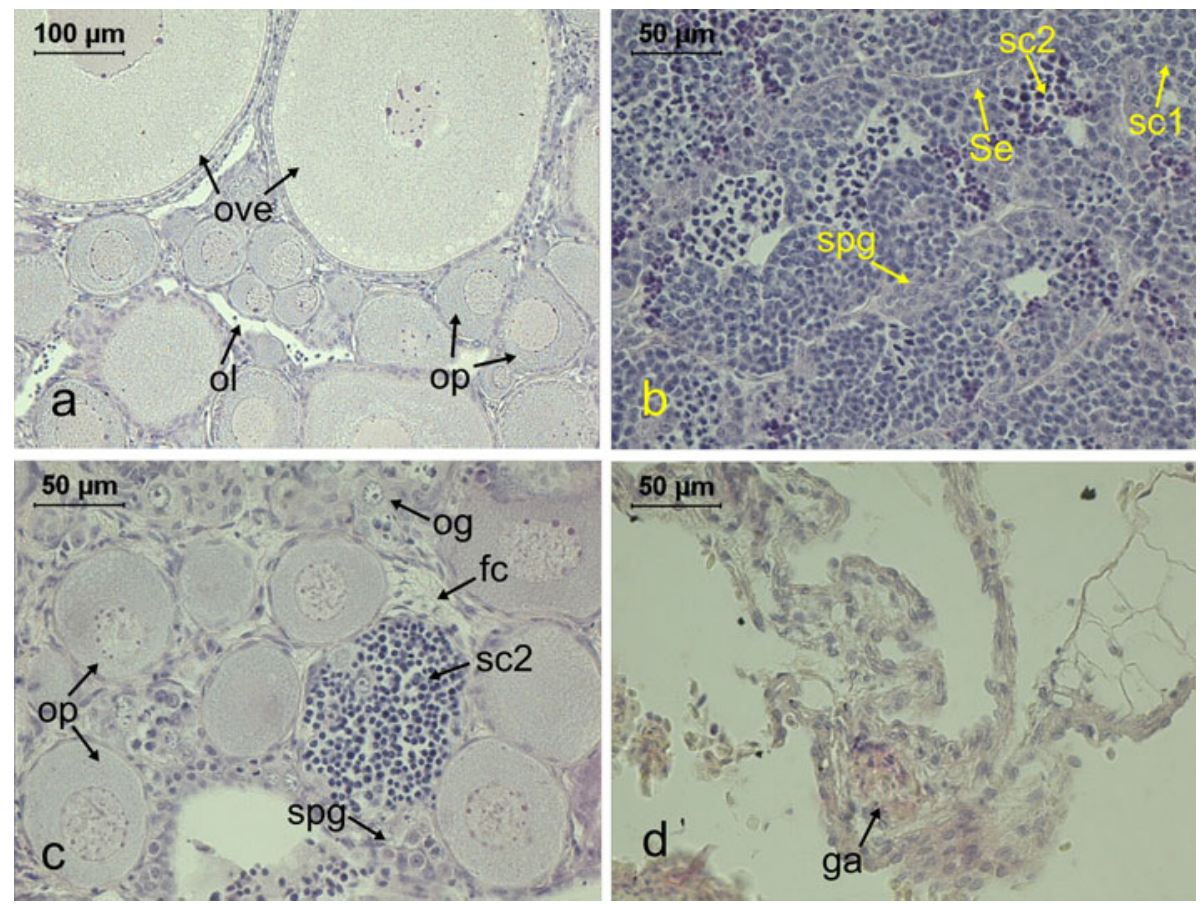

Fig. 2 Haematoxylin and eosin-stained gonad sections of the brook trout (Salvelinus fontinalis) $\times$ Arctic char (Salvelinus alpinus) $\mathrm{F}_{1}$ hybrid female (H17) (a), male (H21) (b), intersex (H34) (c) and sterile (H29) (d) specimens sampled 15 months after hatching. $f c$ follicular cells, ga gonadal anlage, og oogonia, ol ovarian lamellae, ove early vitellogenic oocytes (during endogenic growth), op previtellogenic oocytes, spg spermatogonia, $s c 1$ primary spermatocytes, $s c 2$ secondary spermatocytes, Se Sertoli cells

gonadal component contained oogonia and previtellogenic oocytes, while male component comprised spermatogonia and spermatocytes. Follicular cells were observed to surround both, oocytes and male components in the intersex gonad (Fig. 2c). The gonadal tissue in the two sterile specimens was reduced to the portion of the gonadal anlage (Fig. 2d).

Diploid chromosome numbers in the males and intersex individuals varied from 82 to $84(\mathrm{FN}=99-102)$. Chromosome numbers in the females were $82(\mathrm{FN}=99-100)$ and 83 $(\mathrm{FN}=100)$ chromosomes. Two sterile individuals: $\mathrm{H} 25$ and $\mathrm{H} 29$ exhibited $82(\mathrm{FN}=99)$ and $84(\mathrm{FN}=100)$ chromosomes (respectively) in their somatic cells. Two fish with no microscopically identified gonads showed karyotypes composed of 84 chromosomes $(\mathrm{FN}=100)($ Table 1$)$.

\section{Discussion}

Although cytogenetic traits of the interspecific hybrids are supposed to be intermediate between two parental species, chromosome numbers observed in such specimens may differ from what is expected. Incompatibility between egg cytoplasm of one species and sperm genome of another species sometimes results in the uniparental chromosome elimination observed during early embryogenesis. Male chromosome elimination through the chromosome loss or partial deletion has been observed in the cross between female 
masu salmon (Oncorhynchus masou masou, Brevoort, 1856) and male rainbow trout (Oncorhynchus mykiss, Walbaum 1792) (Fujiwara et al. 1997). Presumably, huge variation in the chromosome number observed among the brook trout $\mathrm{x}$ Arctic char hybrids studied here resulted from both inheritance of the chromosomal polymorphism observed in the parental individuals and de novo chromosome rearrangements (Ohno et al. 1965; Phillips et al. 1999). Variation in the chromosome number observed in the Arctic char from Rutki is attributed to the centric fusion or fission and known as Robertsonian polymorphism (Pomianowski et al. 2012). Therefore, it is reasonable to assume that the Arctic char male used in the experiment was heterozygous for the Robertsonian polymorphism $(2 n=81)$ and provided gametes that differ in the chromosome number $(n=40$ and $n=41)$. Moreover, the post-zygotic fission of one metacentric chromosome into two acrocentric chromosomes or non-disjunction of the sister chromatids might has been responsible for the increase of the chromosome number in the hybrid specimens exhibiting 84 chromosomes. Incompatibility between parental sets of chromosomes may result in reduced fertility or even sterility in the interspecific fish hybrids (Tave 1993; Hulata 1995). Odd chromosome number and the homologous chromosome pairing suppression may impair gonadal development and/or trigger production of the aneuploid gametes (LeGrande et al. 1984; Goudie et al. 1993). That is why decreased reproductive performance observed in the brook trout $\mathrm{x}$ Arctic char hybrids was first of all attributed to the karyological differences between parental species. Nevertheless, we did not find any link between chromosome number and development of the intersexual or sterile gonads in the hybrids studied here.

Sex differentiation process in fish can be modified by genetic, environmental, behavioural and physiological factors (Chan and Yeung 1983; Devlin and Nagahama 2002). Interspecific crosses may change both sex determination and gonadal differentiation processes in the fish hybrid progenies. Predominantly male offspring is produced when the Nile tilapia (Oreochromis niloticus) cross with the blue tilapia (O. aureus) as both species show different sex determination systems (Beardmore et al. 2001). The Nile tilapia has $\mathrm{XX} / \mathrm{XY}$ system with the female being homogametic (XX), whereas blue tilapia has ZZ/ZW system with the male showing both sex chromosomes of the same type (ZZ). Hybridization between the Nile tilapia female and blue tilapia male yields all-male or almost all-male progenies (ZX) (Penman and McAndrew 2000). Anomalies during the anatomical sex differentiation have been found in the whitefish (Coregonus lavaretus L.) and peled (Coregonus peled Gmel.) hybrids where previtellogenic oocytes, vitellogenic oocytes and spermatogonial cells have been found in the course of the histological assay of the gonads (Demska-Zakes and Mamcarz 1996). In the present study, gonadal sex ratio distortion towards males and much bigger portion of the female component in the intersex gonads suggested hybrid char females had problems with gonadal differentiation. Similarly, ovarian development has been observed to be impaired in the Atlantic salmon (Salmo salar) x brown trout (Salmo trutta) hybrids (Youngson et al. 1992). Both parental char species of the hybrids studied here show genetic sex determination (Woram et al. 2003), but probably, their sex chromosomes are at different stages of the morphological differentiation. Indeed, brook trout putative sex chromosomes are two medium-sized metacentric chromosomes (Phillips et al. 2002; Ocalewicz et al. 2004), while Arctic char sex-linked microsatellite DNA sequences have been mapped to one of the largest metacentric chromosome pair (Kwitkowski 2007). Thus, interactions between brook trout and Arctic char sex chromosomes and genes from the sex chromosomes and autosomes rather than unpairing of the parental chromosomes may affect gonadal development in the hybrids.

Reduced fertility observed in the intersex fish may be related to the malformations of the gonoducts, disruption of the testicular lobule structure and inhibition of the 
spermatogenesis (Nolan et al. 2001). Despite the disturbances in the gonadal development, intersex individuals are not sterile. In the case of the brook trout and Arctic char hybrids, interspecific cross followed by the triploidization seems to be a promising approach leading to production of the sterile offspring. Similar attitude has been successfully applied in the Atlantic salmon x brown trout hybrids (Galbreath and Thorgaard 1997).

Acknowledgments We thank Stefan Dobosz and Henryk Kuzminski (Department of Salmonid Research, Inland Fisheries Institute in Olsztyn, Rutki) for kindly providing fish for the studies. We also thank Elzbieta Ziomek (Department of Ichthyology, UWM in Olsztyn) for technical assistance during histological analysis. This work was supported by the Polish National Science Center (NCN), Project No. N N311 525240.

Open Access This article is distributed under the terms of the Creative Commons Attribution License which permits any use, distribution, and reproduction in any medium, provided the original author(s) and the source are credited.

\section{References}

Bartley DM, Rana K, Immink AJ (2001) The use of inter-specific hybrids in aquaculture and fisheries. Rev Fish Biol Fish 10:325-337

Beardmore JA, Mair GC, Lewis RI (2001) Monosex male production in finfish as exemplified by tilapia: applications, problems, and prospects. Aquaculture 197:283-301

Chan STH, Yeung WSB (1983) Sex control and sex reversal in fish under natural conditions. Academic Press, New York, pp 171-222

Demska-Zakes K, Mamcarz A (1996) Gonadal abnormalities in Coregonus peled Gmel. $\times$ Coregonus lavaretus L. hybrids, introduced into natural waters. In: Kirchhofer A, Hefti D (eds) Conservation of endangered freshwater fish in Europe. Birkhauser, Basel, pp 225-232

Devlin RH, Nagahama Y (2002) Sex determination and sex differentiation in fish: an overview of genetic, physiological, and environmental influences. Aquaculture 208:191-364

Fujiwara A, Abe S, Yamaha E, Yamazaki F, Yoshida MC (1997) Uniparental chromosome elimination in the early embryogenesis of the inviable salmonid hybrids between masu salmon female and rainbow trout male. Chromosoma 106:44-52

Galbreath PF, Thorgaard GH (1997) Sexual maturation and fertility of diploid and triploid Atlantic salmon $\times$ brown trout hybrids. Aquaculture 137:299-312

Goudie CA, Tiersch TR, Simco BA, Davis KB, Liu Q (1993) Early growth and morphology among hybrids of ictalurid catfishes. J Appl Aquac 3:235-256

Gross R, Gum B, Reiter R, Kuhn R (2004) Genetic introgression between Arctic charr (Salvelinus alpinus) and brook trout (Salvelinus fontinalis) in Bavarian hatchery stocks inferred from nucleolar and mitochondrial DNA markers. Aquac Int 12:19-32

Hliwa P, Demska-Zakęś K, Martyniak A (2002) Annual ovarian cycle of Vimba vimba (L.) from the Drawienski National Park in northwest Poland. Arch Pol Fish 10:41-50

Hulata G (1995) A review of genetic improvement of the common carp (Cyprinus carpio L.) and other cyprinids by crossbreeding, hybridization and selection. Aquaculture 129:143-157

Kwitkowski K (2007) Identification of teh Arctic char sex-determining chromosome. M.Sc. Thesis, Simon Fraser University

LeGrande WH, Dunham RA, Smitherman RO (1984) Karyology of three species of catfishes (Ictaluridae: Ictalurus) and four hybrid combinations. Copeia 1984:873-878

Nolan M, Jobling S, Brighty G, Sumpter JP, Tyler CR (2001) A histological description of intersexuality in the roach. J Fish Biol 58:160-176

Ocalewicz K, Śliwińska A, Jankun M (2004) Autosomal localization of internal telomeric sites (ITS) in brook trout, Salvelinus fontinalis (Pisces, Salmonidae). Cytogenet Genome Res 105:79-82

Ocalewicz K, Woznicki P, Jankun M (2008) Mapping of rRNA genes and telomeric sequences in Danube salmon (Hucho hucho) chromosomes using primed in situ labeling technique (PRINS). Genetica 134:199-203

Ohno S, Stenius C, Faisst E, Zenzes MT (1965) Post-zygotic chromosomal rearrangements in rainbow trout (Salmo irideus Gibbons). Cytogenetics 4:117-129 
Penman DJ, McAndrew BJ (2000) Genetics for the management and improvement of cultured tilapias. In: Beveridge MCM, McAndrew BJ (eds) Tilapias biology and exploitation. Kluwer, Dordrecht, pp 227-266

Phillips RB, Ráb P (2001) Chromosome evolution in the Salmonidae (Pisces): an update. Biol Rev 76:1-25

Phillips RB, Matsukoa MP, Smoker WW, Gharett AJ (1999) Inheritance of a chromosomal polymorphism in odd-year pink salmon from southeastern Alaska. Genome 42:816-820

Phillips RB, Matsuoka MP, Reed KM (2002) Characterization of charr chromosomes using fluorescence in situ hybridization. Environ Biol Fish 64:223-228

Pomianowski K, Jankun M, Ocalewicz K (2012) Detection of interstitial telomeric sequences in the Arctic charr (Salvelinus alpinus) (Teleostei: Salmonidae). Genome 55:26-32

Schulz RW, de Franca LR, Lareyre JJ, Le Gac F, Chiarini-Garcia H, Nobrega RH, Miura T (2010) Spermatogenesis in fish. Gen Comp Endocrinol 165:390-411

Tave D (1993) Genetics for fish hatchery managers, 2nd edn. Van Nostrand Reinhold, New York

Woram RA, Gharbi K et al (2003) Comparative genome analysis of the primary sex-determining locus in salmonid fishes. Genome Res 13:272-280

Youngson AF, Knox D, Johnstone R (1992) Wild adult hybrids of Salmo salar L. and Salmo trutta L. J Fish Biol 40:817-820

Zawistowski S (1986) Histological techniques, histology and the foundations of histopathology. PZWL, Warszawa in Polish 